$\mathbf{F}$ loral movements have been appointed as mechanisms to avoid selfpollination (Darwin, 1862), and new evidence indicates that they reduce intrafloral male-female interference as well (Barrett, 2003; Sun et al., 2007). Motion occurs in different floral parts: corolla, gynoecium, style, stigma, or stamens, and motility is either insectinduced or active (Ruan and Texeira da Silva, 2011). A recent review on adaptative advantages of floral movement indicated four main benefits: (1) they promote outcrossing, (2) allow delayed selfing, (3) support tolerance to harsh environments, and (4) reduce intrafloral male-female interference (Ruan and Teixeira da Silva, 2011). Investigation of motility of floral elements and its adaptive significance allows understanding evolution of mating systems, ecological habitat shifts and pollinator environments in different groups of plants (Herlihy and Eckert, 2002; Kalisz et al., 2004; Goodwillie et al., 2005; Barrett, 2008). Stamen movement has been documented in a few plant families, among them Berberidaceae (Lechowski and Bialczyk, 1992). Ren (2010) suggested that there are four main types of stamen movement: cascade movement (Weigend and Gottschling, 2006); quick and explosive movement (Taylor et al., 2006); simultaneous and slow movement (Azuma et al., 2005); and stimulated movement (Lechowski and Bialczyk, 1992; Lebuhn and Anderson, 1994). Stamen movement can affect the reproductive biology of flowering plants because this mechanism forces the visitors to enter flowers and may alter the interaction plant-pollinator (Schlindwein and Wittmann, 1997; Edwards et al., 2005; Liu et al., 2006; Ren, 2010).

In the case of Berberidaceae, stamen stimulated movement has been associated with a quick transmembrane flux of ions and subsequent water efflux (Bialczyk and Lechowski, 1988; Lechowski and Bialczyk, 1992). It is usually triggered by insects that visit

\title{
Floral movements: Stamen motion IN BERBERIS TRIFOLIOLATA
}

\author{
Diego F. Angulo, Victoria Sosa ${ }^{1}$ \\ and José G. García-Franco \\ Instituto de Ecología, A.C., Xalapa, Veracruz, Mexico \\ ${ }^{1}$ Author for correspondence: victoria.sosa@inecol.mx
}

and touch stamens, enhancing the probability of the anther/pollen coming into contact with pollinators, or for helping the anther come into contact with a self pistil, promoting autogamy (Ren, 2010).

Here we selected Berberis trifoliolata, a shrub known by common names like agarito, algerita, chiper and palo amarillo to corroborate if a stimulated movement of stamens occurrs in response to contact with visitors as previously reported for Berberidaceae (Lechowski and Bialczyk, 1992) as well as to identify pollinators and floral visitors. Plants of $B$. trifoliolata are small to medium in sized, evergreen shrubs that produce abundant red berries. Agarito is one of the noteworthy species in the arid and semi-arid lands of North America, in the Chihuahuan and Sonoran Deserts and in Tamaulipan thorn scrub.

We conducted fieldwork in two localities, in the foothills of the $\mathrm{Ce}$ rro Potosí in Galeana, Nuevo León, a mountain located in northeastern Mexico in the Chihuahuan Desert (24 $4^{\circ}$ ' $16^{\prime \prime} \mathrm{N}$ and $100^{\circ} 15^{\prime} 12^{\prime \prime} \mathrm{W}$ ). Altitude is approximately $2,100 \mathrm{~m}$ a.s.1. and vegetation is thorny semi- arid scrub. The second study site was located within the Mezquital Valley, a semiarid shrubland at the north of Ixmiquilpan on the southern area of " $\mathrm{Ce}$ ro La Muñeca" in Hidalgo (20 $37^{\circ}$ ' $12.8^{\prime \prime} \mathrm{N}$ and $\left.99^{\circ} 13^{\prime} 44.8^{\prime} \mathrm{W}\right)$. Altitude is approximately 2,129 $\mathrm{m}$ a.s.1. (Figure 1). Observations of floral visitors were made during the flowering peak in March of 2011 and 2012. The behaviour of bees visiting the flowers was observed. To estimate floral visitors a transect method was followed (revised in Dafni et al., 2005) using three transects measuring $10 \times 50 \mathrm{~m}$ along which the frequency, time of occurrence and visit rate were recorded. Each individual within a transect was observed for a 10 minute period from 0700 to $1430 \mathrm{~h}$ over six days in 2011 , and from 0700 to $1700 \mathrm{~h}$ over three days in 2012. Insects were killed with ethyl acetate for identification and deposited in the entomological collection of the Instituto de Ecología, A.C. (IEXA).

Our field observations detected a sweet smell emitted by the corollas throughout anthesis. The number of showy yellow flowers varies from 14 per raceme, and plants usually produce two close racemes. Fruit are red 

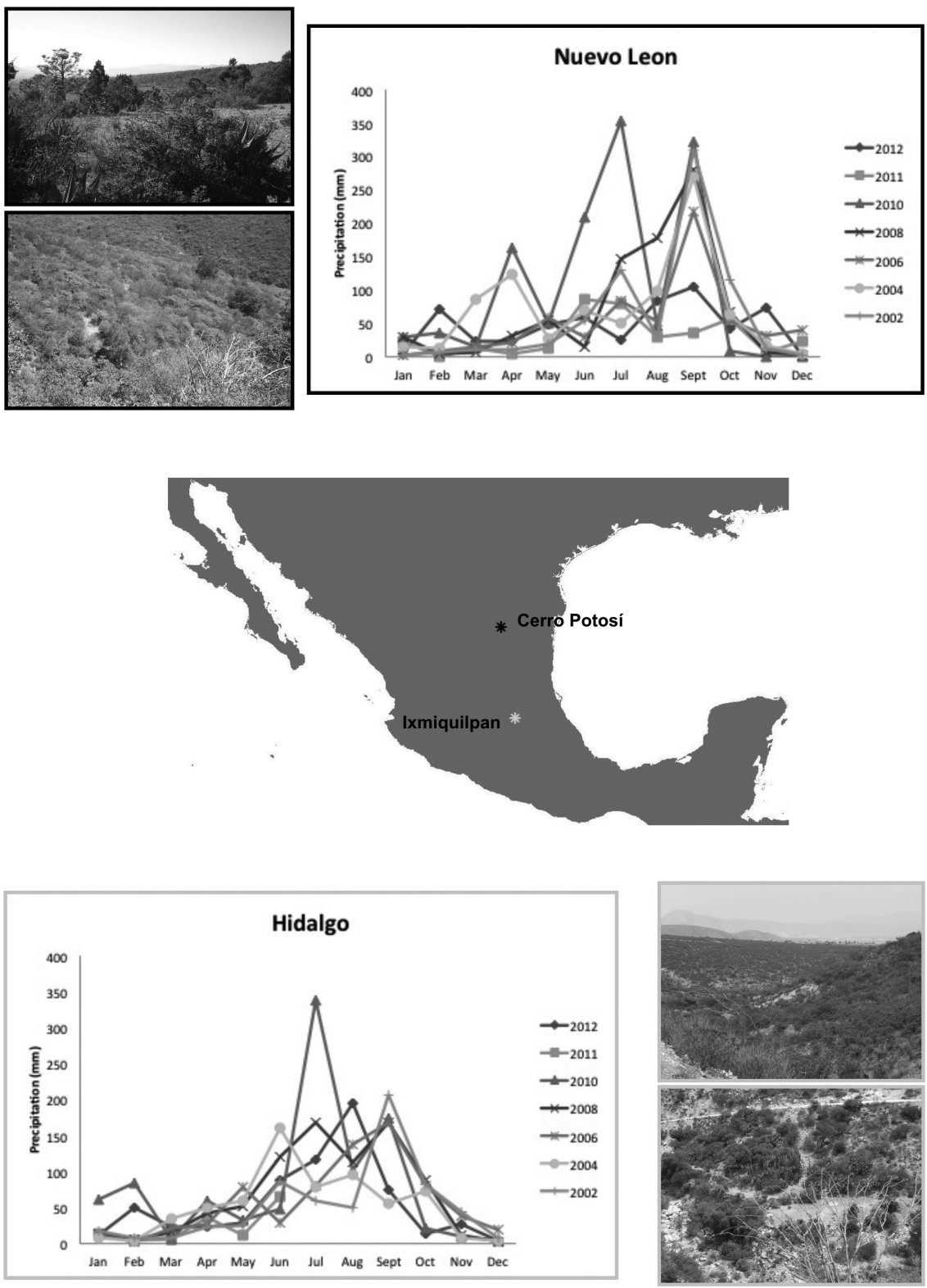

Figure 1. Location of Cerro Potosí, Nuevo León and Ixmiquilpan, Hidalgo, where fieldwork was conducted. Images of Tamaulipan thorn scrub and semiarid shrubland at the Mezquital Valley are included. Precipitation for the last ten years are shown in the graph.

spherical berries that are fleshy and juicy with citrous flavor (Figure 2). Flowering season is in winter-spring. In both field study sites, blooming started in February, reaching a peak by mid-February and continued through early April, ending in late April and early May. Flowers open successively along inflorescences and anthesis last $6 \pm 2$ days $(\mathrm{n}=20)$. At Cerro Potosí, the number of flowers per individual was $194 \pm 87.3(n=10)$. At Ixmiquilpan, the nuber of flowers per individual was $42.5 \pm 24.4(n=8)$.

In both field study sites, in newly opened flowers, the following tripping mechanism occurs: the stamens are pressed to the outside of the flower against the corolla. When the inner surface of the filaments is stimulated by an insect visitor, the filament snaps inward, placing pollen from the anther on the vector. Later, the stamens return to their original position against the corolla. Nectaries are located on both sides of each of the six stamens. When they are touched by visitors probing for nectar, the filaments rapidly propel the anthers to the stigma, placing pollen on the body of the pollinator. Filaments can be folded independently forcing the pollinator to move around the flower and its legs to touch neighboring flowers, thus increasing the amount of pollen that adheres to the insect (Figure 2). In Cerro Potosí, Nuevo León, flower-visiting insects included members of Apidae, Syrphidae and Vespidae. The most common visitor was the honeybee, Apis mellifera. In addition, two species of flies (Copestylum mexicanum and Copestylum sp.), and a social wasp (Vespula sp.) occasionally visited flowers. Our observations in Ixmiquilpan, Hidalgo, detected other pollinators, like the bee Megachile sp. and plants are not pollinated by honeybees. Our field site in Cerro Potosí was surrounded by cornfields and beehives are abundant. Thus, we believe that the abundant populations of Apis mellifera, instead of native bees, pollinated the agarito flowers in this site. It has been discovered that honeybees dominate the pollinator assemblage in sites close to field crops (Sáez et al., 2012).

The tripping pollination mechanism described above facilitates the transport of pollen by an insect that moves among the flowers of different plants, touching receptive stigmas with the pollen on the surface of its body, completing cross-pollination. Bees are important pollinators for other plant species of arid and desert regions in North America (Arizaga $e t$ al., 2000; Clark-Tapia and MolinaFreaner, 2004; Pendleton et al., 2008; Ortíz et al., 2010). Previous research has found that they are the main pollinators in Berberis. Small Adrenidae, Apis mellifera and Bombus sp. have been reported for $B$. thunbergii 


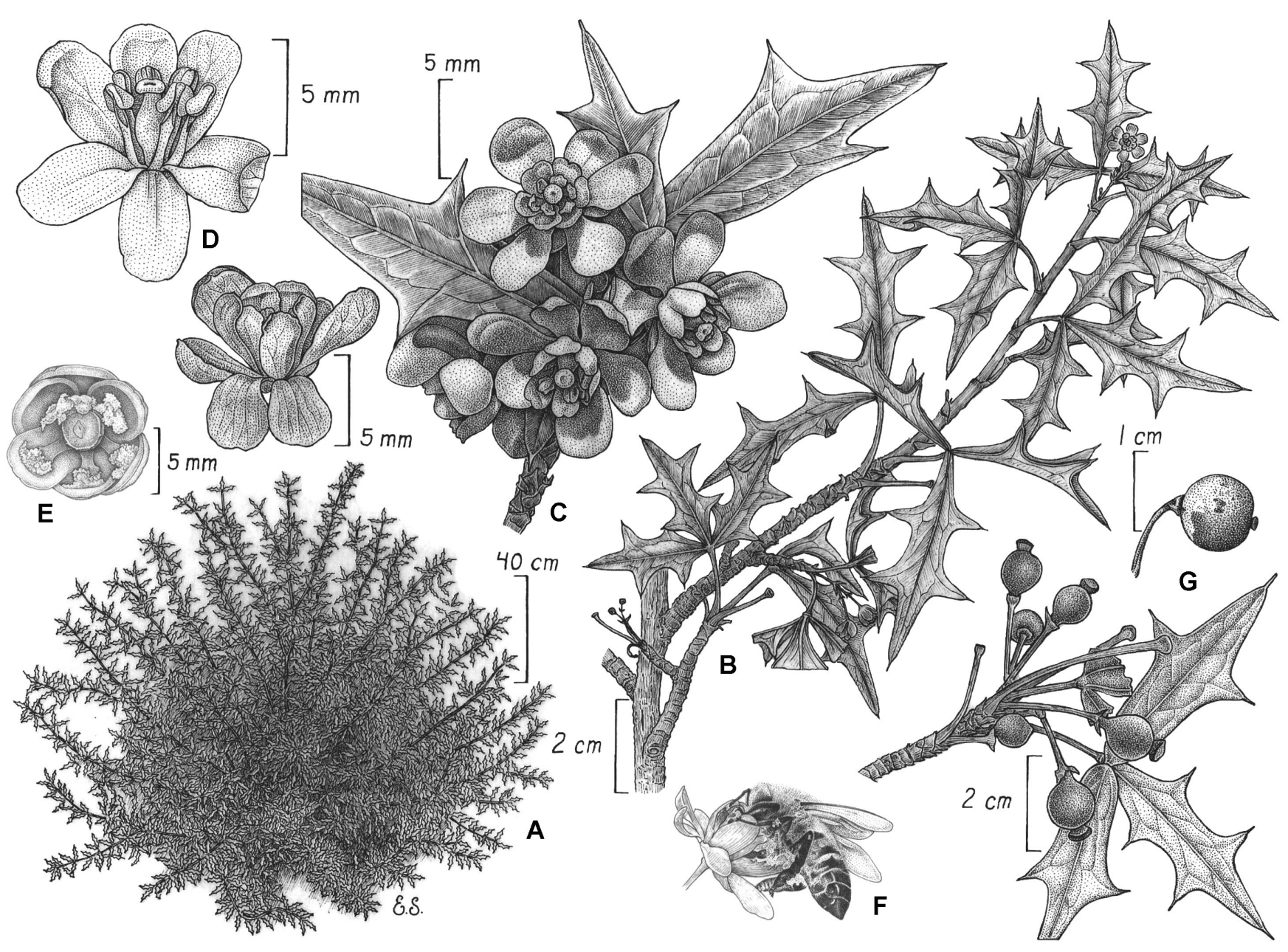

Figure 2. Habit, leaves, inflorescences, details of flowers and fruit of Berberis trifoliolata. A) habit, B) branch, C) inflorescence, D) flower before insect visitation, E) flower with anthers folded after insect visitation, F) honey bee visiting agarito flower, G) branching fruit and berry.

(Lebuhn and Anderson, 1994). Peterson (2003) reported that bees, wasps, flies, and beetles are the pollinators in B. vulgaris. Our results show Apis mellifera to be an effective pollinator for B. trifoliolata. Honeybees are known for moving short distances within the plant favoring transfer of pollen from one flower to another in the same individual (Schaffer et al., 1983; Corbet, 1991).

It has been demonstrated that nectar production in plants from arid and semi-arid lands is influenced by a number of factors such as weather variables like daily maximum temperature and precipitation (Lloyd et al., 2002) or demographic parameters
(Golubov et al., 2004); nectar evaporates at high temperatures (Nocentini et al., 2012). In the case of agarito, nectar was so scarce that we were unable to collect any amount. In Cerro Potosí precipitation was low and temperature was high compared to previous years (see Figure 1). Thus, further questions for study include whether $B$. trifoliolata also produces abundant nectar, if humidity or demographic parameters are correlated to its production and if an increase in the amount of nectar attracts more and native pollinators. Moreover, it has been demonstrated that native bees selects flowers with abundant nectar, rejecting flowers with scarce or without nectar (Aizen et al., 2011).

\section{Acknowledgments}

We thank two anonymous reviewers for helpful comments and suggestions. We thank Edmundo Saavedra for his illustration. We would like to thank Denisse Maldonado, Leticia Monje, Eduardo Ruíz Sánchez, Guillermo Huerta, Raquel Vargas and Jorge Vargas Jr. for their valuable help with the fieldwork. To Jorge Vargas and Florentina Rangel for providing lodging. To Carlos Vergara for identifying insects. Field work was supported by a grant from CONACyT to VS (106060). 


\section{Literature cited}

Aizen M.A., Lozada M. and Morales C.L. 2011. Comparative nectar-foraging behaviors and efficiencies of an alien and a native bumble bee. Biological Invasions 13:2901-2909.

Arizaga S., Ezcurra E., Peters E., Ramírez de Arellano F. and Vega E. 2000. Pollination ecology of Agave macroacantha (Agavaceae) in a Mexican tropical desert. I. Floral biology and pollination mechanisms. American Journal of Botany 87: 1004-1010.

Azuma H., Toyota M. and Asakawa Y. 2005. Floral scent chemistry and stamen movement of Chimonanthus praecox (L.) Link (Calycanthaceae). Acta Phytotaxonomica et Geobotanica 56:197-201.

Barrett S.C.H. 2003. Mating strategies in flowering plants: the outcrossing-selfing paradigm and beyond. Philosophical Transactions of the Royal Society. B. Biological Sciences 358:991-1004.

Barrett S.C.H. 2008. Major evolutionary transitions in flowering plant reproduction: An overview. International Journal of Plant Sciences 169:1-5.

Bialczyk J. and Lechowski, Z. 1988. The seismonastic movements of plant organs. Wiadomosci Botaniczne 32:209226.

Clark-Tapia R. and Molina-Freaner F. 2004. Reproductive ecology of the rare clonal cactus Stenocereus eruca in the Sonoran Desert. Plant Systematics and Evolution 247:155-164.

Corbet S.A. 1991. Applied pollination ecology. Trends in Ecology and Evolution 6:3-4.

Dafni, A., Kevan, P. G., and Husband, B. C. 2005. Practical pollination biology. Enviroquest, Ontario.

Darwin C. 1862 . On the various contrivances by which British and foreign orchids are fertilized by insects. John Murray, London.

Edwards J., Whitaker D., Klionsky S. and Laskowski M.J. 2005. A record-breaking pollen catapult. Nature 435: 164 .

Golubov J., Mandujano M.C., Montaña
C., López-Portillo J. and Eguiarte L.E. 2004. The demographic costs of nectar production in the desert perennial Prosopis glandulosa (Mimosoideae): a modular approach. Plant Ecology 170:267-275.

Goodwillie C., Kalisz S. and Eckert C.G. 2005. The evolutionary enigma of mixed mating systems in plants: occurrence, theoretical explanations, and empirical evidence. Annual Review of Ecology, Evolution and Systematics 36:47-79.

Herlihy C.R. and Eckert C.G. 2002. Genetic cost of reproductive assurance in a self-fertilizing plant. Nature 416:320-323.

Kalisz S., Vogler D.W. and Hanley K.M. 2004. Context-dependent autonomous self-fertilization yields reproductive assurance and mixed mating. Nature 430:884-887.

Lebuhn G. and Anderson G.J., 1994. Anther tripping and pollen dispensing in Berberis thunbergii. The American Midland Naturalist 131:257-265.

Lechowski Z. and Bialczyk J. 1992. Effect of external calcium on the control of stamen movement in Berberis vulgaris L. Biologia Plantarum 34:121-130.

Liu K.W., Liu Z.J., Huang L.Q., Li L.Q., Chen L.J. and Tang G.D. 2006. Selffertilization strategy in an orchid. $\mathrm{Na}$ ture 441:945-946.

Lloyd S., Ayre D.J. and Whelan R.J. 2002. A rapid and accurate visual assessment of nectar production can reveal patterns of temporal variation in Banksia ericifolia (Proteaceae). Australian Journal of Botany 50:595-600.

Nocentini D., Pacini E., Guarnieri M. and Nepi M. 2012. Flower morphology, nectar traits and pollinator of Cerinthe major (Boraginaceae-Lithospermae). Flora 207:186-196.

Ortíz F., Stoner K.E., Pérez-Negrón E. and Casas A. 2010. Pollination biology of Myrtillocactus schenckii (Cactaceae) in wild and managed populations of the Tehuacán Valley, Mexico. Journal of Arid Environments 74:897-904.

Pendleton R.L., Pendleton B.K., Wetherill
K.R. and Griswold T. 2008. Reproductive biology of Larrea tridentata: A preliminary comparison between core shrubland and isolated grassland plants at the Sevilleta National Wildlife Refuge, New Mexico. USDA Forest Service Proceedings RMRS-P 52:131-135.

Peterson P.D. 2003. The common barberry: the past and present situation in Minnesota and the risk of wheat stem rust epidemics. Ph.D. Dissertation. North Carolina State University. 199 pp.

Ren M.X. 2010. Stamen movements in hermaphroditic flowers: diversity and adaptive significance. Chinese Journal of Plant Ecology 34:867-875.

Ruan C.J. and Teixeira da Silva J.A. 2011. Adaptive significance of floral movement. Critical Reviews in Plant Sciences 30:293-328.

Sáez A., Sabatino M. and Aizen M. 2012. Interactive effect of large- and smallscale sources of feral honey-bees for sunflower in the Argentine pampas. Plos One 7:e30968.

Schaffer W.M., Zeh D.W., Buchmann S.L., Kleinhans S., Valentine Schaffer M. and Antrim J. 1983. Competition for nectar between introduced honey bees and native North American bees and ants. Ecology 64:564- 577.

Schlindwein C. and Wittmann D. 1997. Stamen movement in flowers of Opuntia (Cactaceae) favour oligolectic pollinators. Plant Systematics and Evolution 204:179-193.

Sun S., Gao J.Y., Liao W.J., Li Q.J. and Zhang D.Y. 2007. Adaptive significance of flexistyly in Alpinia blepharocalyx (Zingiberaceae): a hand- pollination experiment. Annals of Botany 99:661666.

Taylor P.E., Card G., House J., Dickinson M.H. and Flagan R.C. 2006. Highspeed pollen release in the white mulberry tree, Morus alba L. Sexual Plant Reproduction 19.19-24.

Weigend M. and Gottschling M. 2006. Evolution of funnel-revolver flowers and ornithophily in Nasa (Loasaceae). Plant Biology 8:120-142.

Received: March 19th, 2013

Accepted: June 25th, 2013 